\title{
A different approach of dizziness in older patients: away from the diagnostic dance between patient and physician
}

\section{Otto R. Maarsingh ${ }^{1,2}$, Hanneke Stam ${ }^{1,2}$ and Henriëtte E. van der Horst ${ }^{1,2}$}

1 Department of General Practice and Elderly Care Medicine, VU University Medical Center, Amsterdam, Netherlands

${ }^{2}$ EMGO Institute for Health and Care Research, VU University Medical Center, Amsterdam, Netherlands

\section{Edited by:}

Frank Sullivan, University of Toronto, Canada

Reviewed by:

Kees Van Boven, Radboud University Nijmegen, Netherlands

José Luis Ballvé, Hospitalet de Llobregat, Spain

*Correspondence:

Otto R. Maarsingh, Department of General Practice and Elderly Care Medicine, EMGO Institute for Health and Care Research, VU University Medical Center, Van der

Boechorststraat 7, Room D528,

Amsterdam 1081 BT, Netherlands

e-mail: o.maarsingh@vumc.nl
Although the etiology of dizziness in older patients differs significantly from that of younger patients, most guidelines on dizziness advocate the same diagnosis-oriented approach for all patients regardless of their age. However, this diagnosis-oriented approach may be insufficient for older patients presenting with dizziness in general practice, because (1) general practitioners are often not able to identify an underlying cause of dizziness, (2) general practitioners regularly identify causes of dizziness that cannot be treated, and (3) general practitioners may identify causes of dizziness for which treatment is available but not desirable. In this article, the authors present a simultaneous diagnosis- and prognosisoriented approach for older dizzy patients. This approach may enable general practitioners to improve their care for a voluminous group of impaired older patients, even if a diagnosis is not available (yet).

Keywords: dizziness, older people, prognosis, diagnosis, general practice
Dizziness - like falling and incontinence - is one of the geriatric giants. Thirty percent of people above 65 years of age experience some form of dizziness, increasing to $50 \%$ in persons above 85 years (1). Nine percent of all persons above 65 years visit their general practitioner (GP) at least once a year because of dizziness (2). The complaint dizziness can lead to severe limitations in daily functioning (3). Dizziness is also a major risk factor for falling (4), thus leading to further limitation of activities, fractures, and high healthcare costs (5).

Although the etiology of dizziness in older patients differs significantly from that of younger patients, most guidelines on dizziness advocate the same diagnosis-oriented approach for all patients regardless of their age. However, this diagnosis-oriented approach may be insufficient for older patients presenting with dizziness. Firstly, GPs are often not able to identify an underlying cause of dizziness [ $40-80 \%$ of older dizzy patients in general practice; $(2,6)]$. Secondly, GPs regularly identify causes of dizziness that cannot be treated (e.g., polyneuropathy, 19\% of older dizzy patients in general practice) or hardly treated [e.g., orthostatic hypotension, $24 \%$ of older dizzy patients; (7)]. Finally, GPs may identify causes of dizziness for which treatment is available but not desirable [e.g., Epley maneuver for benign paroxysmal positional vertigo in patients with severe cervical arthrosis; (8)].

When applied to older patients with chronic dizziness $[70 \%$ of older dizzy patients in primary care have a dizziness onset of $\geq 6$ months ago; (7)], the current diagnosis-oriented approach is not only insufficient but may also have negative side-effects. When a GP is not able to identify an underlying cause of dizziness, patient and GP may persist in a diagnostic dance, leading to extensive testing and unnecessary referral $(9,10)$. An absent diagnosis and consequently - clues for therapeutic interventions may also lead to inappropriate drug prescribing. Data from the Second Dutch National Survey of General Practice (DNSGP-2) show that GPs prescribed ineffective drugs to $10 \%$ of dizzy older patients during the first consultation (11). Eventually, a GP may indulge in therapeutic nihilism: "dizziness comes with age" or "you will have to live with this."

Previously, other researchers emphasized the limitations of the current diagnosis-oriented approach of dizziness. In 1999, Sloane and Dallara already expressed the need for strategies that more effectively reduce symptoms and dizziness-related disability (12). In 2000, Tinetti and others suggested that considering dizziness, a geriatric syndrome might lay the groundwork for such an impairment reduction strategy (3). Geriatric syndromes are multifactorial health conditions that occur when the accumulated effect of impairments in multiple systems renders a person vulnerable to situational challenges. More recently, other researchers supported this concept of dizziness as a geriatric syndrome (13-16).

When focusing on underlying causes of dizziness, it is easy to neglect individual prognostic differences. Dros and others found that $34 \%$ of older dizzy patients in general practice will experience persistent dizziness-related impairment after 6 months (17). They found dizziness-related impairment at baseline [as measured with the Dizziness Handicap Inventory, DHI; (18)] to be the strongest predictor of persistent dizziness-related impairment. Additionally, they identified seven predictors of persistent dizziness-related impairment, namely (1) dizziness onset of more than 6 months ago, (2) dizziness provoked by standing still, (3) associated trouble with walking, (4) polypharmacy, (5) absence of diabetes mellitus (explanation: diabetes may be a marker for attentive medical care), (6) presence of anxiety or depression, and (7) impaired functional mobility (17). The research group also constructed a 
seven-item sum score to calculate the probability of persistent dizziness-related impairment (17). An example, when applying the score calculation in a patient $\mathrm{X}$ with chronic dizziness provoked by standing still and associated with walking, using six drugs and having a comorbid depression and impaired functional mobility, the probability of persistent dizziness-related impairment in patient $\mathrm{X}$ changes from 34 to $85 \%$. Even if patient X's GP is not able to identify an underlying cause of dizziness (yet), patient $\mathrm{X}$ has three predictors of persistent impairment that are amenable to treatment, namely (1) polypharmacy (treatment: medication reduction), (2) depression (psychotherapy and/or antidepressants), and (3) impaired functional mobility (physiotherapy).

For the clinical approach of chronic dizziness in older patients in primary care, we would like to suggest to replace the current "serial connection" between diagnosis and prognosis by a "parallel connection," i.e., the diagnosis-oriented phase and prognosis-oriented phase start at the same time (see Figure 1). Currently, GPs are used to focus on prognosis after diagnosing a specific disease, for example, investigating the presence of albuminuria - as a marker for kidney disease - after diagnosing diabetes mellitus. In other words, the prognosis-oriented phase ("is this patient at risk of an unfavorable outcome and, if so, how to improve this outcome?") follows the diagnosis-oriented phase ("what is the underlying cause of the presented complaint?"). We believe that the suggested "parallel connection" of diagnosis and prognosis is crucial for older dizzy patients in primary care, because many older dizzy patients remain undiagnosed but have clues for impairment reduction $(3,13,14)$.

For daily clinical practice, the suggested additional prognosisoriented approach could imply that a GP tries (1) to estimate if an older dizzy patient is at risk of persistent impairment [by using the DHI and the seven-item sum score; $(17,18)]$ and, if so, (2) to identify modifiable predictors of an unfavorable course of dizziness. Examples of previously identified modifiable predictors are impaired functional mobility [treatment: physical exercise or physiotherapy; (17)], comorbid anxiety [psychotherapy and/or anxiolytics; $(17,19)]$, comorbid depression [psychotherapy and/or antidepressants; (17)], dizziness due to psychiatric causes [psychotherapy and/or psychotropic drugs; (20)], polypharmacy

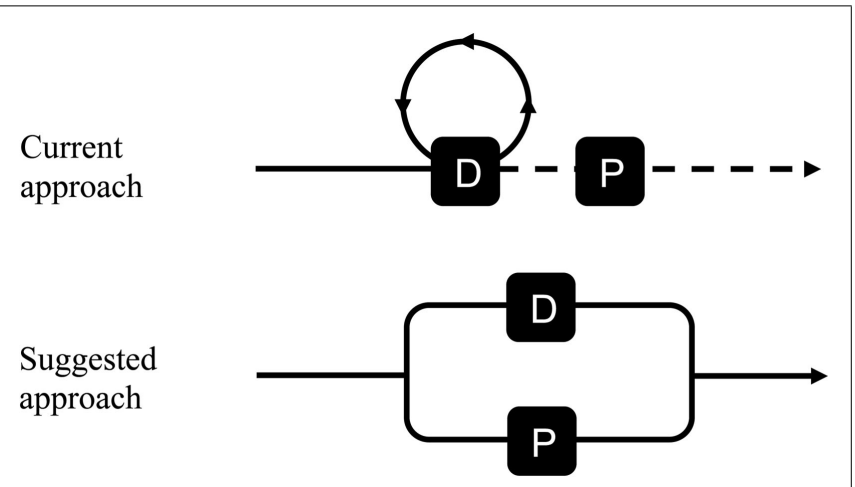

FIGURE 1 | Schematic representation of current and suggested approach of chronic dizziness in older patients in general practice (D, diagnosis-oriented phase; $P$, prognosis-oriented phase). [medication reduction; (17)], and the presence of avoidance [cognitive behavioral therapy; (21)].

Finally, we do not want to advocate diagnostic nihilism. The suggested approach should not be at the expense of a thorough diagnostic evaluation. Benign paroxysmal positional vertigo, for example, is a cause of dizziness in older patients that can be easily diagnosed [history taking and Hallpike maneuver; (22)] and effectively treated [Epley maneuver; $(8,23)]$. The clinical approach of dizziness in older patients requires personalized care, though, in which it is necessary to find a delicate balance between excessive testing and diagnostic nihilism.

\section{CONCLUSION}

The current diagnosis-oriented approach does not suit older patients presenting with dizziness. A simultaneous diagnosis- and prognosis-oriented approach for older dizzy patients may enable GPs to improve their care for a voluminous group of impaired older patients, even if a diagnosis is not available (yet). Hopefully, such an approach will not only improve the patient's quality of life, but also reduce inappropriate drug prescribing and unnecessary referral.

\section{ACKNOWLEDGMENTS}

The first author (Otto R. Maarsingh) was supported by an individual grant of the Stichting Beroepsopleiding Huisartsen (SBOH) in The Netherlands.

\section{REFERENCES}

1. Jonsson R, Sixt E, Landahl S, Rosenhall U. Prevalence of dizziness and vertigo in an urban elderly population. J Vestib Res (2004) 14:47-52.

2. Maarsingh OR, Dros J, Schellevis FG, van Weert HC, Bindels PJ, van der Horst HE. Dizziness reported by elderly patients in family practice: prevalence, incidence, and clinical characteristics. BMC Fam Pract (2010) 11:2. doi:10.1186/1471-2296-11-2

3. Tinetti ME, Williams CS, Gill TM. Dizziness among older adults: a possible geriatric syndrome. Ann Intern Med (2000) 132(5):337-44. doi:10.7326/00034819-132-5-200003070-00026

4. Agrawal Y, Carey JP, La Santina CC, Schubert MC, Minor LB. Disorders of balance and vestibular function in US adults: data from the National Health and Nutrition Examination Survey, 2001-2004. Arch Intern Med (2009) 169:938-44. doi:10.1001/archinternmed.2009.66

5. Scuffham P, Chaplin S, Legood R. Incidence and costs of unintentional falls in older people in the United Kingdom. J Epidemiol Community Health (2003) 57:740-4. doi:10.1136/jech.57.9.740

6. Kruschinski C, Kersting M, Breull A, Kochen MM, Koschack J, HummersPradier E. Frequency of dizziness-related diagnoses and prescriptions in a general practice database. Z Evid Fortbild Qual Gesundhwes (2008) 102(5):313-9. doi:10.1016/j.zefq.2008.05.001

7. Maarsingh OR, Dros J, Schellevis FG, van Weert HC, van der Windt DA, Ter Riet $\mathrm{G}$, et al. Causes of persistent dizziness in elderly patients in primary care. Ann Fam Med (2010) 8(3):196-205. doi:10.1370/afm.1116

8. Hilton MP, Pinder DK. The Epley (canalith repositioning) manoeuvre for benign paroxysmal positional vertigo (2004, update 2010). Cochrane Database Syst Rev (2010). doi:10.1002/14651858.CD003162.pub2

9. Van der Weijden T, Van Bokhoven MA, Dinant GJ, Van Hasselt CM, Grol RP. Understanding laboratory testing in diagnostic uncertainty: a qualitative study in general practice. Br J Gen Pract (2002) 52(485):974-80.

10. Van der Weijden T, Van Velzen M, Dinant GJ, Van Hasselt CM, Grol RP. Unexplained complaints in general practice: prevalence, patients' expectations, and professionals' test-ordering behavior. Med Decis Making (2003) 23(3):226-31. doi:10.1177/0272989X03023003004

11. Maarsingh OR, Schellevis FG, van der Horst HE. Looks vestibular: irrational prescribing of antivertiginous drugs for older dizzy patients in general practice. Br J Gen Pract (2012) 62(603):518-20. doi:10.3399/bjgp12X656757 
12. Sloane PD, Dallara J. Clinical research and geriatric dizziness: the blind men and the elephant. J Am Geriatr Soc (1999) 47:113-4.

13. Gassmann KG, Rupprecht R. Dizziness in an older community dwelling population: a multifactorial syndrome. J Nutr Health Aging (2009) 13:278-82. doi:10.1007/s12603-009-0073-2

14. Gomez F, Curcio CL, Duque G. Dizziness as a geriatric condition among rural community-dwelling older adults. J Nutr Health Aging (2011) 15:490-7. doi:10.1007/s12603-011-0050-4

15. de Moraes SA, Soares WJ, Ferriolli E, Perracini MR. Prevalence and correlates of dizziness in community-dwelling older people: a cross sectional population based study. BMC Geriatr (2013) 13:4. doi:10.1186/1471-2318-13-4

16. Stevens KN, Lang IA, Guralnik JM, Melzer D. Epidemiology of balance and dizziness in a national population: findings from the English Longitudinal Study of Ageing. Age Ageing (2008) 37:300-5. doi:10.1093/ageing/afn019

17. Dros J, Maarsingh OR, van der Windt DA, Oort FJ, ter Riet G, de Rooij SE, et al. Functional prognosis of dizziness in older primary care patients: a prospective cohort study. J Am Geriatr Soc (2012) 60(12):2263-9. doi:10.1111/jgs.12031

18. Jacobson GP, Newman CW. The development of the Dizziness Handicap Inventory. Arch Otolaryngol Head Neck Surg (1990) 116(4):424-7. doi:10.1001/ archotol.1990.01870040046011

19. Bailey KE, Sloane PD, Mitchell M, Preisser J. Which primary care patients with dizziness will develop persistent impairment? Arch Fam Med (1993) 2(8):847-52. doi:10.1001/archfami.2.8.847

20. Kroenke K, Lucas C, Rosenberg ML, Scherokman B, Herbers JE. One-year outcome for patients with a chief complaint of dizziness. J Gen Intern Med (1994) 9(12):684-9. doi:10.1007/BF02599010
21. Nazareth I, Yardley L, Owen N, Luxon L. Outcome of symptoms of dizziness in a general practice community sample. Fam Pract (1999) 16(6):616-8. doi:10.1093/fampra/16.6.616

22. Barraclough K, Bronstein A. Vertigo. BMJ (2009) 339:b3493. doi:10.1136/bmj. b3493

23. Glasziou P, Heneghan C. Epley and the slow boat from research to practice. Evid Based Med (2008) 13(2):34-5. doi:10.1136/ebm.13.2.34-a

Conflict of Interest Statement: The authors declare that the research was conducted in the absence of any commercial or financial relationships that could be construed as a potential conflict of interest.

Received: 06 July 2014; paper pending published: 04 November 2014; accepted: 17 November 2014; published online: 01 December 2014.

Citation: Maarsingh OR, Stam H and van der Horst HE (2014) A different approach of dizziness in older patients: away from the diagnostic dance between patient and physician. Front. Med. 1:50. doi: 10.3389/fmed.2014.00050

This article was submitted to Family Medicine and Primary Care, a section of the journal Frontiers in Medicine.

Copyright (c) 2014 Maarsingh, Stam and van der Horst. This is an open-access article distributed under the terms of the Creative Commons Attribution License (CC BY). The use, distribution or reproduction in other forums is permitted, provided the original author(s) or licensor are credited and that the original publication in this journal is cited, in accordance with accepted academic practice. No use, distribution or reproduction is permitted which does not comply with these terms. 